\title{
Endovascular Management of Intracranial Dural AVFs: Transvenous Approach
}

(D) K.D. Bhatia, (D) Hee, (D). Kortman, (D). Klostranec, (D). Guest, (D). Wälchli, (DI. Radovanovic, (D)T. Krings, and (D) V.M. Pereira

\begin{abstract}
SUMMARY: In this third review article on the endovascular management of intracranial dural AVFs, we discuss transvenous embolization approaches. Transvenous embolization is increasingly popular and now the first-line approach for ventral dural AVFs involving the cavernous sinus and hypoglossal canal. In addition, transvenous embolization is increasingly used in lateral epidural dural AVFs in high-risk locations such as the petrous and ethmoid regions. The advantage of transvenous embolization in these locations is the ability to retrogradely embolize the draining vein and fistula while reducing the risk of ischemic cranial neuropathy or brain parenchymal infarction commonly feared from a transarterial approach. By means of coils \pm ethylene-vinyl alcohol copolymer, transvenous embolization can achieve angiographic cure rates of $80 \%-90 \%$ in ventral locations. Potential complications include transient cranial neuropathy, neurologic deterioration due to venous outflow obstruction, and perforation while navigating pial veins. Transvenous embolization should be considered when dural AVFs arise in proximity to the vasa nervosum or extracranial-intracranial anastomoses.
\end{abstract}

ABBREVIATIONS: $\mathrm{CCF}=$ carotid cavernous fistula; $\mathrm{dAVF}=$ dural AVF; ECA = external carotid artery; EC-IC = external carotid to internal carotid; EVOH = ethylene-vinyl alcohol copolymer; IPS = inferior petrosal sinus; JR-NET3 = Japanese Registry of Neuro Endovascular Therapy; RPC = reverse pressure cooker; $\mathrm{TAE}=$ transarterial embolization; TVE $=$ transvenous embolization

I this third review article on the endovascular management of intracranial dural AVFs (dAVFs), we discuss transvenous approaches. Transvenous embolization (TVE) is an increasingly popular approach for the treatment of intracranial $\mathrm{dAVF}$ and the preferred approach for ventral skull base locations due to the risk of cranial neuropathy from arterial approaches. ${ }^{1,2}$ Treatment goals, favorable anatomic locations, technical approaches, alternative access strategies, outcomes, and complications are discussed in this review.

Received February 5, 2021; accepted after revision July 9

From the Division of Neuroradiology (K.D.B., H.L., H.K., J.K., W.G., T.K., V.M.P.) and Division of Neurosurgery (T.W., I.R., T.K., V.M.P.), Toronto Western Hospital, Toronto, Ontario, Canada; Division of Medical Imaging (K.D.B.), Sydney Children's Hospital Network, Westmead, New South Wales, Australia; Division of Paediatrics (K.D.B.), Faculty of Medicine, University of Sydney, Camperdown, New South Wales, Australia; Division of Paediatrics (K.D.B.), Faculty of Medicine, University of New South Wales, Kensington, New South Wales, Australia; Division of Medical Imaging (K.D.B.), Faculty of Medicine, Macquarie University, Macquarie Park, New South Wales, Australia; Department of Neurosurgery (H.L.), Stanford University School of Medicine, Stanford, California; Division of Neuroradiology (H.K.), Elisabeth-TweeSteden Ziekenhuis Hospital, Tilburg, the Netherlands; Division of Interventional Neuroradiology (J.K.), McGill University Health Centre, Montreal, Quebec, Canada; and Division of Interventional Neuroradiology (W.G., V.M.P.), St. Michael's Hospital, Toronto, Ontario, Canada.

Please address correspondence to Kartik Dev Bhatia, MD, Department of Medical Imaging, Sydney Children's Hospital Network, Corner Hawkesbury Rd and Hainsworth St, Westmead, NSW, 2145, Australia; e-mail: Kartik.bhatia@health.nsw.gov.au

- Indicates open access to non-subscribers at www.ajnr.org

http://dx.doi.org/10.3174/ajnr.A7300

\section{Treatment Goals}

As with all treatment approaches to intracranial dAVFs, the clinical goal of TVE is to reduce the risk of future hemorrhage or nonhemorrhagic neurologic deficits (see the first article in this series on Principles). Therefore, disconnection of dangerous cortical venous reflux is more important than angiographic cure of the dAVF. In selected low-risk benign dAVFs (Borden I/Cognard I), the clinical goal is, instead, to ameliorate disabling symptoms such as intractable pulsatile tinnitus.

TVE can be considered analogous to microsurgical disconnection for dAVFs in that the angiographic goal is to follow the proximal venous course and occlude the proximal aspect of the draining vein or sinus, ie, the "foot" of the vein. ${ }^{3}$ By means of a retrograde approach to the fistulous point, TVE with ethylenevinyl alcohol copolymer (EVOH) and/or coils can occlude the foot of the draining vein and the fistulous point in situations in which transarterial embolization (TAE) is technically difficult or dangerous. ${ }^{4}$ Also analogous to microsurgery, ${ }^{3,5}$ disconnection of cortical venous reflux can downgrade the dAVF from an aggressive to a benign lesion.

\section{Indications}

TVE is indicated for dAVFs in which TAE approaches are associated with a moderate risk of the following:

1. Ischemic cranial neuropathy due to adjacent vasa nervosum 


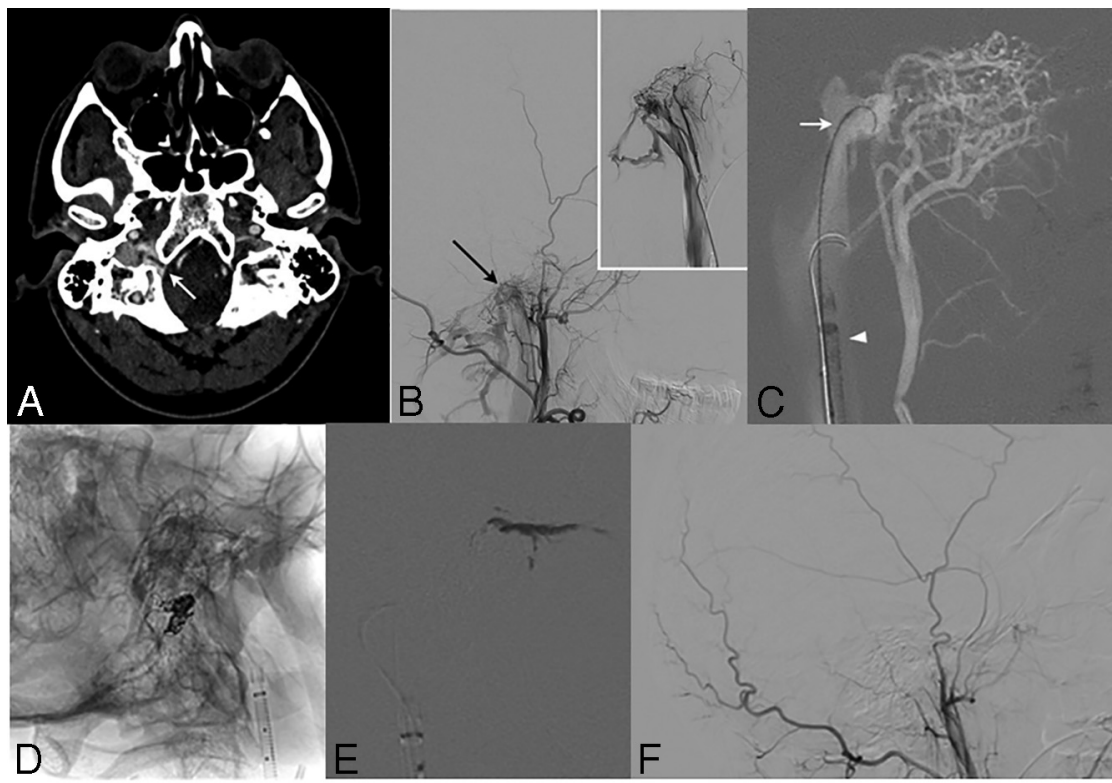

FIG 1. Transvenous embolization of a right hypoglossal canal (anterior condylar) dAVF using a reverse pressure cooker technique in a 47-year-old man for management of refractory pulsatile tinnitus. A, CT angiogram (axial) demonstrates increased vascularity surrounding the right hypoglossal canal (white arrow) with arterialization of the right anterior condylar vein, suggestive of a dAVF. B, Right lateral ECA cerebral angiography confirms the diagnosis, with primary arterial supply via neuromeningeal trunk branches (black arrow) of the right ascending pharyngeal artery (inset, selective right ascending pharyngeal artery injection). C, Lateral fluoroscopy roadmap of transvenous treatment shows a 6F Destination sheath (Terumo) positioned in the right internal jugular vein (white arrowhead), through which a SONIC $1.5 \mathrm{~F}$ microcatheter (Balt) with a $4.5-\mathrm{cm}$ detachable tip was positioned at the fistulous point (white arrow). D, A 1.5F Marathon microcatheter (Covidien) was placed in the anterior condylar confluence to deploy 7 detachable coils, with the coil mass demonstrated in the working projection. E, The Marathon microcatheter was removed, and the SONIC microcatheter was primed with dimethyl-sulfoxide before forming an Onyx (Covidien) cast at the fistulous point. F, Right ECA lateral projection angiography demonstrates complete occlusion of the fistula.

2. Parenchymal infarction from external carotid to internal carotid (EC-IC) anastomoses

3. Inability to reach a distal embolization position due to tortuosity or small-vessel caliber.

These anatomic and angioarchitectural factors are particularly associated with dAVFs adjacent to the ventral skull base ${ }^{2}$ (eg, cavernous, condylar, or clival). However, increasing use of TVE techniques for lateral and dorsal dAVFs is a notable trend. ${ }^{4,6-8}$

\section{Anatomic Locations}

In this series of articles, in addition to using the Borden and Cognard classification systems, we also reference the classification system of Geibprasert et $\mathrm{al}^{1}$ when stratifying dAVFs by anatomic locations. This classification system, based on the anatomic-embryologic venous drainage pattern of the fistula and divided into ventral, lateral, and dorsal epidural groups, ${ }^{1}$ is detailed in the first article in this series (Principles).

TVE is particularly useful in ventral skull base locations due to these dAVFs involving external carotid artery (ECA) branches to the blood supply of cranial nerves that traverse the ventral skull base foramina. ${ }^{1}$ These ventral locations also have extensive adjacent EC-IC or external carotid-vertebral artery anastomoses. ${ }^{2}$
Ventral locations for which TVE is now the most common approach include the cavernous sinus and ventral aspect of the foramen magnum (eg, hypoglossal canal). ${ }^{9-13}$ An example of a TVE for a hypoglossal canal dAVF is demonstrated in Fig 1.

Carotid-cavernous fistulas (CCFs) can be divided into direct (Barrow classification type A) and indirect (Barrow B-D) types. ${ }^{14}$ Direct CCFs involve a single-hole high-flow communication between the cavernous ICA and the cavernous sinus, occurring after trauma or dissection. ${ }^{9}$ Indirect CCFs are multihole dAVFs that drain into the cavernous sinus and are, therefore, analogous to other dAVFs being considered in this series of articles. ${ }^{9,14,15}$ Direct CCFs represent a different type of disease than other dAVFs, and their management lies beyond the scope of this article but has been well-described. ${ }^{15,16}$ The endovascular treatment of indirect CCFs (Barrow B-D), historically undertaken using TAE, has evolved with TVE now the established first-line approach. ${ }^{9,13,15}$ A sample case of TVE for bilateral indirect CCFs is demonstrated in Fig 2.

Petrous dAVFs, though lateral epidural in location, also pose a potential risk of facial nerve palsy during TAE because they receive at least partial arterial supply from vessels that form the facial nerve arterial arcade. ${ }^{4}$ Petrous dAVFs can be treated via TAE, TVE, or microsurgical disconnection, with the proximity of the fistulous point to the facial arcade being the primary consideration. ${ }^{4}$ TVE and microsurgical disconnection for petrous dAVFs both aim to occlude the draining superior petrosal vein of Dandy. ${ }^{3-5}$ A sample case of TVE for a petrous dAVF with proximity to the facial arcade is demonstrated in Fig 3.

Ethmoidal dAVFs, embryologically also classified as lateral epidural shunts, ${ }^{1}$ pose a risk of retinal artery occlusion during TAE due to their supply via the ethmoidal branches of the ophthalmic artery. ${ }^{17}$ Additionally, the tortuosity and small caliber of the ethmoidal arteries can hinder distal microcatheter access. ${ }^{6,8}$ Ethmoid dAVFs are surgically accessible by an anterior cranial fossa approach, and this approach is typically the primary treatment. ${ }^{3,17,18}$ However, TVE is increasingly used as an alternative to craniotomy, with recent evidence that TVE has a significantly improved cure rate compared with TAE with low complication rates. ${ }^{6,8}$

Other lateral epidural shunts that can be approached with TVE include falcotentorial dAVFs, which are often supplied by small-caliber arterial feeders from the ICA (meningohypophyseal trunk branches) and posterior circulation (posterior meningeal artery, artery of Davidoff and Schechter), which make TAE approaches more 


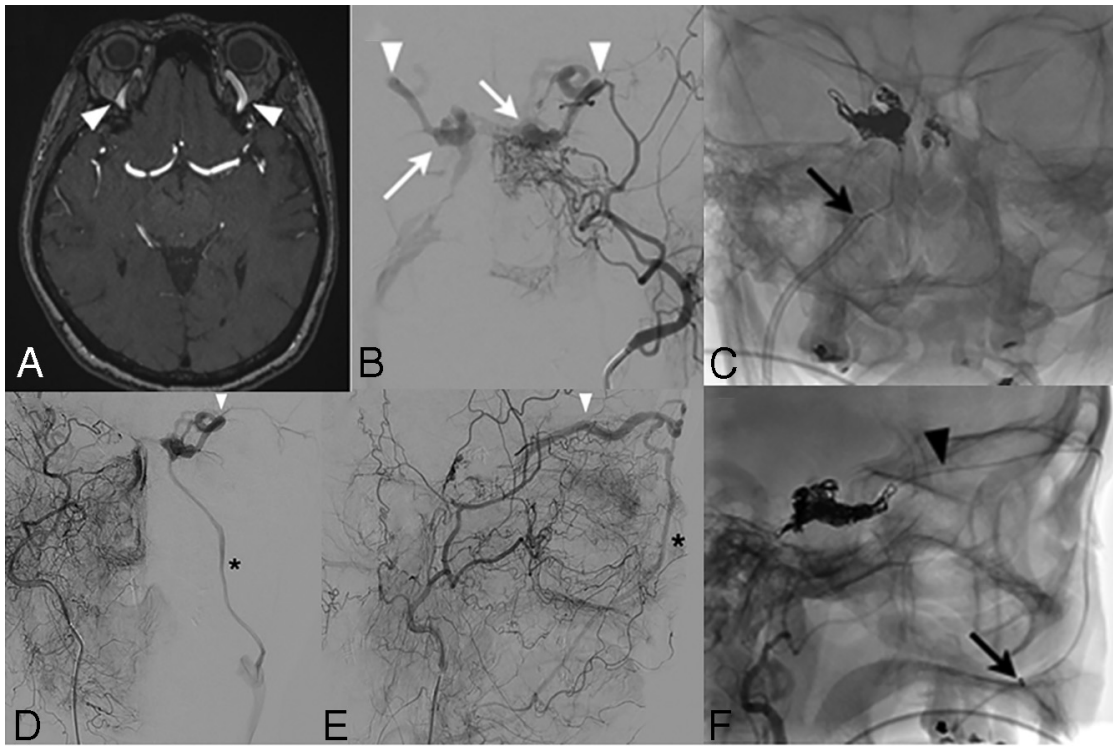

FIG 2. Bilateral indirect CCFs treated with transvenous embolization via right inferior petrosal sinus and left facial vein approaches. A, A 64-year-old woman presented with right-sided ptosis and loss of vision, investigated with a TOF-MRA that demonstrates arterialization of the bilateral superior ophthalmic veins (white arrowheads). B, Frontal-projection left ECA angiography demonstrates an indirect CCF with supply from dural branches of the bilateral ECAs and ICAs, with the right cavernous sinus opacifying earlier than the left (white arrows) and reflux into the bilateral superior ophthalmic veins (white arrowheads). C, Transvenous treatment fluoroscopy in a frontal projection shows positioning of a $6 \mathrm{~F}$ Envoy catheter (Cordis) (black arrow) into the proximal right inferior petrosal sinus, with an Excelsior SL-10 microcatheter (Stryker) advanced into the right cavernous sinus. Subsequent coil embolization of the proximal right superior ophthalmic vein, right cavernous sinus, and medial left cavernous sinus through the intercavernous sinus was followed by injection of 33\% glue (Glubran $n$-BCA; GEM Italy) in Lipiodol (Guerbet) into the right-sided coil mass. There was resolution of the patient's symptoms; however, a few weeks later she developed left-sided chemosis. Frontal $(D)$ and lateral $(E)$ projection right ECA angiography demonstrates progression in the left cavernous sinus arteriovenous shunting, with prominence of the left superior ophthalmic (white arrowhead) and facial (asterisk) veins. No outflow is identified into the left inferior petrosal sinus, which is likely thrombosed. $F$, Lateral-projection fluoroscopy shows how a $6 \mathrm{~F}$ Navien intermediate catheter (Covidien) was advanced via the left internal jugular vein into the left facial vein (black arrow) mounted on a Prowler Plus microcatheter (Codman Neurovascular). The Prowler Plus was then navigated through the left facial, angular, and superior ophthalmic veins into the left cavernous sinus (black arrowhead) and used to embolize with coils.

difficult. ${ }^{5,7}$ However, because these dAVFs predominantly drain into the vein of Galen, detailed angiographic assessment is required to ensure that the deep cerebral structures are not still dependent on the vein of Galen for venous outflow.

A traditional TVE approach for transverse sinus dAVFs (dorsal epidural location) is sinus sacrifice via transvenous coil occlusion. ${ }^{19-21}$ However, this approach in isolation has suboptimal outcomes: In a large study of 150 patients with transverse-sigmoid dAVFs, $64 \%$ required additional TAE procedures following TVE coil occlusion. ${ }^{20}$ In addition, this approach may not be feasible in patients with a contralateral hypoplastic sinus. Deconstructive approaches to transverse-sigmoid dAVFs are progressively being replaced by reconstructive TAE approaches with venous sinus balloon protection (see the second article in this series on TAE). ${ }^{21,22}$ As our knowledge of the angioarchitecture of transverse-sigmoid dAVFs has evolved, there is increasing awareness of a parasinus or common arterial collector in the wall of many of these dAVFs that can be selectively targeted via TVE. ${ }^{23}$
Another dorsal epidural location that can be considered for TVE includes the superior sagittal sinus, which can receive extensive bilateral arterial feeders converging on a long segment of the sinus, rendering TAE more difficult. If the healthy brain is not dependent on that segment of the sinus, as is typical due to the high-flow nature of the dAVF, transvenous sacrifice of the sinus segment can be curative. ${ }^{19}$

Technical Approaches. Technical approaches for TVE include the following:

1. Coil occlusion

2. $\mathrm{EVOH}$ ( \pm coil) occlusion

3. Reverse pressure cooker (RPC) technique

4. Reverse dual-lumen balloon microcatheter.

As a general principle of TVE, arterial access is also required to obtain intraprocedural angiography and roadmap guidance. This is because venography alone will not visualize the fistulous points and will be unable to determine whether the embolization has been successful in obliterating the dAVF.

\section{Coil Occlusion}

TVE using coil occlusion of the draining sinus has been used since the 1990s and is still a common approach for indirect CCFs and transverse-sigmoid sinus dAVFs. ${ }^{10,15,19,20}$ The technique involves transvenous placement of a guide catheter in the ipsilateral jugular vein (usually via femoral access, though upper limb access is also feasible ${ }^{24}$ ); microcatheter advancement into the draining sinus usually via the inferior petrosal sinus (IPS) when treating cavernous dAVFs; $;{ }^{915}$ and construction of an occlusive coil mass with the aim of inducing complete thrombosis of the sinus (Fig 2). ${ }^{19}$ Due to the extensive number of coils required and associated financial costs, the use of pushable or fibered coils is described. ${ }^{25}$

Successful obliteration rate for indirect CCFs using TVE with coils alone was reported as $87 \%$ in a large multicenter series of 267 patients, identifying a lower complication rate using coils alone compared with other embolic agents. ${ }^{26}$ In a series of anterior condylar dAVFs, TVE with coils resulted in a cure in 9 of 14 cases. $^{27}$

\section{EVOH Occlusion}

$\mathrm{EVOH}$ is increasingly popular because it can be used to progressively occlude the proximal aspect of the draining vein and fistulous points in a controlled fashion, resulting in higher rates of 


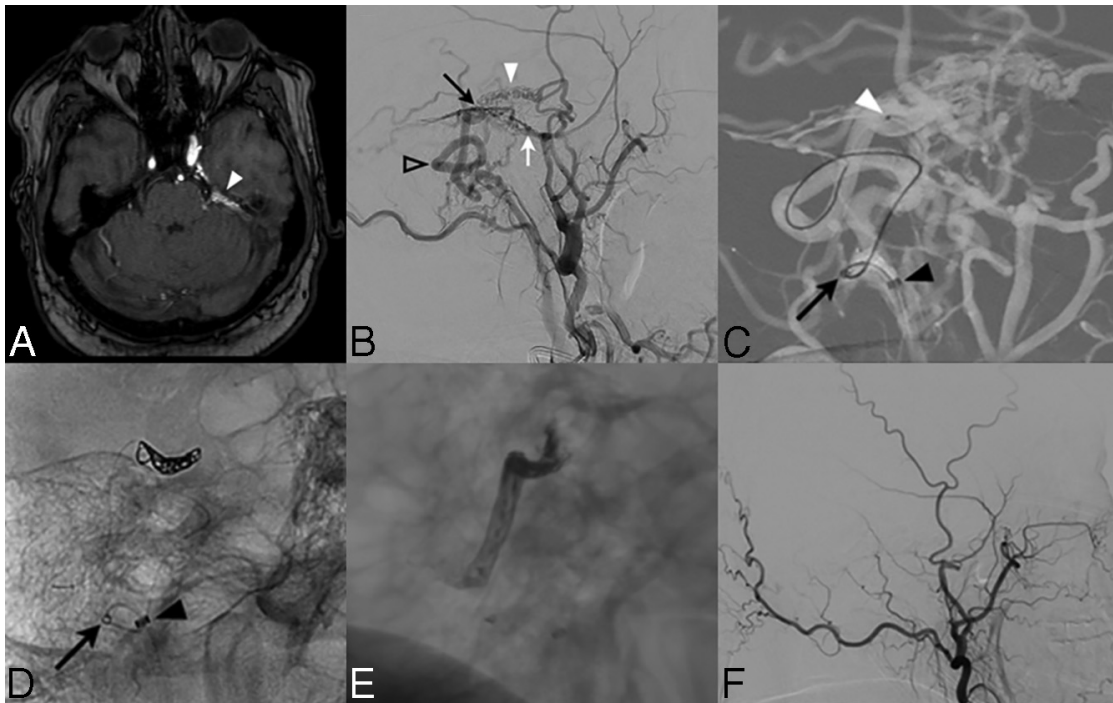

FIG 3. Transvenous embolization of a left petrous ridge dAVF using a modified reverse pressure cooker technique. A 49-year-old man presented with a 3-month history of headache and leftsided pulsatile tinnitus. A, TOF-MRA demonstrates prominence of vessels along the left petrous ridge with arterialization of the left superior petrosal vein of Dandy (white arrowhead). $B$, Lateralprojection left ECA angiography confirms the presence of a left petrous dAVF centered on the superior petrosal vein of Dandy (black arrow), with direct cortical venous drainage (open arrowhead) supplied by left middle meningeal artery petrous branches (white arrow) and a left accessory meningeal artery (white arrowhead). C, Transvenous treatment was performed to avoid embolization of the neighboring facial arcade. A left ECA roadmap in a lateral projection demonstrates a $6 \mathrm{~F}$ Destination sheath placed in the left internal jugular vein (black arrowhead), with a Fargo-Mini intermediate catheter (Balt Extrusion) (black arrow) used to support advancement of a Marathon microcatheter to the fistulous site (white arrowhead). Lateral-projection fluoroscopy was performed after 3 coils were deployed $(D)$ and then after Onyx-18 was used to embolize the distal arterial feeders, fistula site, and proximal draining vein, creating a coil-Onyx mass (E). This was a modification of the reverse pressure cooker technique using a single flow-directed microcatheter (Marathon) without a detachable tip to perform both the coiling and the EVOH injection. This modification was required due to the extensive tortuosity of the transvenous course that impeded attempts to place 2 microcatheters and required the use of a low-profile intermediate catheter (Fargo-Mini) (black arrow). The Marathon microcatheter could not be removed and was left in situ and cut at the level of the right femoral subcutaneous soft tissue. This procedure is typically well-tolerated in the venous system, and the patient was placed on a 6-month course of anticoagulation. F, Follow-up lateral-projection left ECA angiography at 6 months demonstrates complete occlusion of the fistula.

significant cortical venous reflux, classified as Borden type III. ${ }^{36}$ However, even in this situation transvenous access to the isolated segment can be difficult due to the distal thrombosis. ${ }^{37}$

Hypoglossal/condylar dAVFs at the ventral aspect of the foramen magnum can also be treated using $\mathrm{EVOH}$ alone. ${ }^{38}$ However, because the anterior condylar vein drains directly into the internal jugular vein and then the pulmonary circulation, the formation of a coil mass before embolization with EVOH has the advantages of reducing the flow rate and creating a "scaffold" on which EVOH can accumulate and then extend in a retrograde fashion into the fistulous point rather than down the internal jugular vein, allowing more control of the agent (Fig 1). Alternatively, placement of a sinusprotection balloon in the sigmoid sinus/internal jugular vein while embolizing the anterior condylar vein using EVOH is described. ${ }^{39}$

\section{RPC Technique}

The RPC technique is a transvenous modification of the original transarterial pressure cooker technique described by Chapot et al, ${ }^{40}$ in 2014. In the original technique (described in detail in the second article in this series), flow control is achieved by placing 2 microcatheters side by side in the vessel of interest, with placement of an occlusive coil/glue mass adjacent to the detachable tip of a second microcatheter. ${ }^{40}$ $\mathrm{EVOH}$ is then administered via the

cure. $^{28-32}$ The successful use of EVOH alone during TVE has been described for indirect CCFs and is associated with shorter procedural and fluoroscopy times. ${ }^{33}$ Because the microcatheter can be advanced into the constrained space of the cavernous sinus and the goal of treatment in this situation is occlusion of the sinus, indirect CCFs are an ideal indication for EVOH. However, the ability of EVOH to retrogradely penetrate arterial feeders can increase the risk of temporary or even permanent cranial neuropathy. Higher complication rates have been described when using $\mathrm{EVOH}$ alone for the treatment of indirect CCFs. $^{26}$

Transverse-sigmoid dAVFs are classically not well-suited for TVE using EVOH alone due to the large diameter of the sinus and the large venous outflow back to the pulmonary circulation, factors that will necessarily predispose to EVOH deposition in the lungs. ${ }^{34}$ An exception to this statement would be transverse-sigmoid dAVFs with an isolated segment, ${ }^{35}$ where there is thrombotic occlusion proximal and distal to the sinus drainage point resulting in detachable-tip microcatheter with the advantages of maintained antegrade flow and limited reflux. In the RPC technique, the coil/ glue mass and detachable-tip microcatheter are placed in the draining vein, allowing flow reversal in the vein, with retrograde transmission of EVOH to reach the fistulous point. ${ }^{41}$

When undertaking the transvenous RPC technique, the detachable-tip microcatheter is advanced via venous access as close as possible to the foot of the draining vein, to minimize the amount of embolic agent required. This procedure may require navigation across tortuous draining pial veins, during which a gentle technique and use of a tight J-curve on the microwire are useful to reduce the risk of venous rupture. Two sample cases using transvenous RPC technique are demonstrated in Figs 1 and 3.

\section{Dual-Lumen Balloon Retrograde Embolization Technique}

As with TAE, TVE could also be undertaken using a dual-lumen balloon microcatheter with the balloon inflated in the draining vein. In our experience, the seal created by the balloon in 
distensible veins is suboptimal to achieve sustained retrograde flow of EVOH.

\section{Postoperative Management}

Overnight admission to an intensive care or high-dependency unit is required for all our patients following embolization for a dAVF. In addition, if a large segment of the draining vein has been occluded during the TVE procedure or there is sluggish flow in adjacent veins on the final control angiogram, we typically anticoagulate the patient with heparin for 24 hours to avoid excess venous thrombosis. Because venous thrombosis can result in adjacent edema and inflammatory changes that can cause significant headache, we frequently place patients on a weaning course of dexamethasone for 1-2 weeks in these cases.

Alternative-Access Techniques. Alternative-access techniques play an important role in TVE, particularly for the treatment of cavernous $^{42}$ and transverse-sigmoid dAVFs. ${ }^{43}$ Indirect CCFs have at least 8 potential venous exit pathways from the cavernous sinus. ${ }^{44,45}$ Thrombosis of $\geq 1$ of these channels can result in venous outflow limitation, leading to increased pressure and cortical venous reflux. ${ }^{46}$ The most accessible venous pathway to reach the cavernous sinus is via the IPS (Fig $2 A-C$ ), but this can be limited by the presence of IPS thrombosis.

\section{Recanalization of the IPS}

In the presence of a nonvisualized IPS on angiography, considerations include a hypoplastic IPS or thrombosis of a normal/ enlarged IPS. Assessment of CT using thin-section bone window reconstructions allows visualization of the inferior petrosal sulcus, a bony groove formed at the junction of the basiocciput and petrous temporal bone. In the presence of a congenital hypoplastic IPS, the inferior petrosal sulcus may be asymmetrically small. If the IPS is thrombosed, recanalization can be undertaken ${ }^{42}$ by cannulating the ostium of the IPS at the anteromedial surface of the jugular bulb with an angled-tip guide catheter through which an angled tip 0.035 hydrophilic Glidewire (Terumo Inc., Japan) is gently rotated across the thrombosis to create a channel. A microcatheter can then be advanced across the channel to reach the cavernous sinus. ${ }^{42}$ The Glidewire can be removed under negative roadmap conditions to demonstrate the pathway under fluoroscopy. ${ }^{35}$ These same techniques are also useful for gaining access across an occluded transverse sinus to reach an isolated segment. ${ }^{35}$

\section{Transfacial Venous Access}

In the setting of IPS thrombosis, the inferior and superior ophthalmic veins are an alternative access approach. ${ }^{42}$ These can be reached by cannulating the facial vein from the internal jugular vein and then navigating across the angular vein to reach the ophthalmic veins. ${ }^{47,48}$ A sample case of venous access to an indirect CCF via the facial vein is demonstrated in Fig $2 D-F$.

\section{Transorbital Access}

Direct cutdown over the eyelid for access to the superior ophthalmic vein and cavernous sinus was first described by Uflacker et $\mathrm{al}^{49}$ for management of traumatic direct CCFs. The technique was later adapted for treatment of indirect CCFs. ${ }^{33,50}$ Because the superior ophthalmic vein can be tortuous and easily displaced within the orbital fat, it can be difficult to achieve stable access. Thus, direct transorbital access to the cavernous sinus is useful, using a micropuncture needle via an infra- or supraocular approach to reach the inferior or superior orbital fissures and thus cannulate the cavernous sinus at its anterior margin. ${ }^{50} \mathrm{~A} 4 \mathrm{~F}$ dilator and microcatheter can then be used to deploy coils and/or EVOH. $^{51}$

\section{Open Surgical Access}

Open surgical access to the transverse sinus via a burr-hole or craniotomy is well-described to allow placement of occlusive coils superior to a thrombosed sinus segment. ${ }^{43,52}$ Similarly, a subtemporal or even endoscopic surgical approach can allow access to the cavernous sinus. ${ }^{53}$

Outcomes. The Japanese Registry of NeuroEndovascular Therapy (JR-NET3) published the largest known dataset for TVE of cranial dAVFs. ${ }^{10}$ TVE alone was undertaken in 910 cases with the use of coils in $97 \%$ of cases (liquid embolics in only $2 \%$ ). ${ }^{10}$ Favorable clinical outcomes (30-day mRS score of 0-2) were achieved in $92 \%$ of cases. ${ }^{10}$

Cavernous dAVFs treated with TVE alone demonstrated complete angiographic occlusion rates of $87 \%$ in a large series of 199 patients $^{26}$ and $81 \%$ in another series of 141 patients. $^{54}$ Transvenous coil packing for transverse-sigmoid dAVFs in a large series by Kuwayama, ${ }^{55}$ in $2016(n=389)$, resulted in angiographic cure in $53.2 \%$. A systematic review of TVE for hypoglossal/condylar dAVFs identified an angiographic occlusion rate of $93 \% .^{12}$

These results suggest that TVE using coils $\pm \mathrm{EVOH}$ results in angiographic cure in $80 \%-90 \%$ of cases at ventral anatomic locations for which TVE is indicated. The much larger JR-NET3 dataset had a lower angiographic cure rate $(68 \%)$, but liquid embolic agents were used in only $2 \%$ of cases owing to restricted access to EVOH in Japan. ${ }^{10}$

Complications. The JR-NET3 database identified complications in $7.8 \%$ of cases of TVE $(n=71)$ with mortality of $0.7 \%$ and morbidity of $2.8 \% .{ }^{10}$ Complication rates were higher for dAVFs at the craniocervical junction (15.8\%) than for those at the transversesigmoid $(7.3 \%)$ or cavernous $(8.7 \%)$ sinus. ${ }^{10}$ The most common complications (in descending order) were nonhemorrhagic neurologic deterioration resulting from venous occlusion, vessel perforation, hemorrhage from venous occlusion, and arterial thromboembolic events. ${ }^{10}$ Transient cranial nerve palsy following TVE of cavernous dAVFs was not discussed by the JR-NET3 authors but has been reported as occurring in $11 \%$ of TVE cases. ${ }^{56}$ Conservative monitoring and oral corticosteroids are generally effective for such cases. ${ }^{2,54,56}$

\section{Complications Related to Venous Occlusion}

Hemorrhagic and nonhemorrhagic neurologic complications can occur from TVE procedures due to nontarget venous occlusion or venous rerouting, resulting in congestion and infarction. ${ }^{10,56-58}$ Occlusion of venous outflow pathways, even when intended, can result in rerouting of venous flow from the normal brain parenchyma. In most instances, accessory venous pathways will compensate, but occasionally such pathways are lacking due to anatomic variation or thrombotic disease. ${ }^{56-59}$ Venous congestion 
and infarction with neurologic deterioration following TVE have been described when treating cavernous ${ }^{56,59}$ and transverse sinus ${ }^{57}$ dAVFs, most often impacting the cerebellum.

Similarly, patients undergoing microvascular decompression for trigeminal neuralgia can have cerebellar venous infarction if the superior petrosal vein of Dandy is sacrificed intraoperatively and there are limited alternative outflow pathways. ${ }^{60}$ While these cases are rare, the common theme appears to be that normal brain (particularly cerebellar) parenchymal venous outflow pathways should be assessed on pre-embolization angiography.

EVOH embolization with resultant thrombotic occlusion of the cavernous sinus during embolization of cavernous AVFs, though being part of the treatment goal, typically results in swelling and inflammatory change. These can cause transient or even permanent neuropathy of cranial nerves III-VI. ${ }^{26,59,61}$ A weaning course of corticosteroids for 4-6 weeks is typically helpful in these situations. ${ }^{26,59}$ Nontarget retrograde filling of arterial feeders is also a concern if excess EVOH is used, which could result in transmission of EVOH into the ICA, causing parenchymal infarction. ${ }^{59,61}$

The advantages of a transvenous route when treating dural AVFs include lower risks of cranial neuropathy or transmission of the embolic agent across EC-IC anastomoses compared with TAE. These advantages are partially offset by the increased risks of venous congestion or rupture of a pial vein when navigating tortuous draining veins to reach the fistulous point. Thus, the choice of TVE versus TAE should be made on the basis of the individual angioarchitecture of each dAVF. When a transvenous approach to the fistulous point is easily accessible and the length of the draining vein likely to be occluded during embolization is short, TVE is probably safer than TAE options.

\section{CONCLUSIONS}

TVE is now the first-line treatment for ventral dAVFs and is increasingly used for some lateral dAVFs due to the lower risks of cranial nerve palsy or embolization across EC-IC anastomoses. Angiographic cure rates of $80 \%-90 \%$ can be achieved with TVE in these locations. Potential complications include transient cranial neuropathy, neurologic deterioration from venous occlusion, and vessel perforation.

Disclosures: Timo Krings: UNRELATED: Consultancy: Stryker, Penumbra, Medtronic, Cerenovus Royalties: Thieme Stock/Stock Options: Marblehead. Vitor Mendes Pereira: RELATED: Consulting Fee or Honorarium: Medtronic, Comments: research fellow support.

\section{REFERENCES}

1. Geibprasert S, Pereira V, Krings T, et al. Dural arteriovenous shunts: a new classification of craniospinal epidural venous anatomical bases and clinical correlations. Stroke 2008;39:2783-94 CrossRef Medline

2. Geibprasert S, Pongpech S, Armstrong D, et al. Dangerous extracranial-intracranial anastomoses and supply to the cranial nerves: vessels the neurointerventionalist needs to know. AJNR Am J Neuroradiol 2009;30:1459-68 CrossRef Medline

3. Radovanovic I, Wallace M. Cranial dural arterovenous fistula disconnection. In: Jandial R, McCormick P, Black P, eds. Core Techniques in Operative Neurosurgery. Elsevier; 2019

4. Bhatia KD, Kortman $\mathrm{H}$, Lee $\mathrm{H}$, et al. Facial nerve arterial arcade supply in dural arteriovenous fistulas: anatomy and treatment strategies. AJNR Am J Neuroradiol 2020;41:687-92 CrossRef Medline
5. Lawton MT, Sanchez-Mejia RO, Pham D, et al. Tentorial dural arteriovenous fistulae: operative strategies and microsurgical results for six types. Neurosurgery 2008;62:110-24; discussion 124-25 CrossRef Medline

6. Dabus G, Kan P, Diaz C, et al. Endovascular treatment of anterior cranial fossa dural arteriovenous fistula: a multicenter series. Neuroradiology 2020;63:259-66 CrossRef Medline

7. Bhatia KD, Kortman H, Walchli T, et al. Artery of Davidoff and Schechter supply in dural arteriovenous fistulas. AJNR Am J Neuroradiol 2020;41:300-04 CrossRef Medline

8. Roa JA, Dabus G, Dandapat S, et al. Ethmoidal dural arteriovenous fistulas: endovascular transvenous embolization technique. $J$ Neurointerv Surg 2020;12:610 CrossRef Medline

9. Henderson AD, Miller NR. Carotid-cavernous fistula: current concepts in aetiology, investigation, and management. Eye (Lond) 2018;32:164-72 CrossRef Medline

10. Hiramatsu M, Sugiu K, Hishikawa T, et al. Results of 1940 embolizations for dural arteriovenous fistulas: Japanese Registry of Neuroendovascular Therapy (JR-NET3). J Neurosurg 2019 Jun 28 [Epub ahead of print] CrossRef Medline

11. Hellstern V, Aguilar-Pérez M, Schob S, et al. Endovascular treatment of dural arteriovenous fistulas of the anterior or posterior condylar vein: a cadaveric and clinical study and literature review. Clin Neuroradiol 2019;29:341-49 CrossRef Medline

12. Spittau B, Millán DS, El-Sherifi S, et al. Dural arteriovenous fistulas of the hypoglossal canal: systematic review on imaging anatomy, clinical findings, and endovascular management. $J$ Neurosurg 2015;122:883-903 CrossRef Medline

13. Ducruet AF, Albuquerque FC, Crowley RW, et al. The evolution of endovascular treatment of carotid cavernous fistulas: a single-center experience. World Neurosurg 2013;80:538-48 CrossRef Medline

14. Barrow DL, Spector RH, Braun IF, et al. Classification and treatment of spontaneous carotid-cavernous sinus fistulas. J Neurosurg 1985;62:248-56 CrossRef Medline

15. Miller NR. Diagnosis and management of dural carotid-cavernous sinus fistulas. Neurosurg Focus 2007;23:E13 CrossRef Medline

16. Chi CT, Nguyen D, Duc VT, et al. Direct traumatic carotid cavernous fistula: angiographic classification and treatment strategies-study of 172 cases. Interv Neuroradiol 2014;20:461-75 CrossRef Medline

17. Agid R, Terbrugge K, Rodesch G, et al. Management strategies for anterior cranial fossa (ethmoidal) dural arteriovenous fistulas with an emphasis on endovascular treatment. J Neurosurg 2009;110:7984 CrossRef Medline

18. Mayfrank L, Reul J, Huffmann B, et al. Microsurgical interhemispheric approach to dural arteriovenous fistulas of the floor of the anterior cranial fossa. Minim Invasive Neurosurg 1996;39:74-77 CrossRef Medline

19. Roy D, Raymond J. The role of transvenous embolization in the treatment of intracranial dural arteriovenous fistulas. Neurosurgery 1997;40:1133-41; discussion 1141-44 CrossRef Medline

20. Kirsch M, Liebig T, Kuhne D, et al. Endovascular management of dural arteriovenous fistulas of the transverse and sigmoid sinus in 150 patients. Neuroradiology 2009;51:477-83 CrossRef Medline

21. Xu K, Yang X, Li C, et al. Current status of endovascular treatment for dural arteriovenous fistula of the transverse-sigmoid sinus: a literature review. Int J Med Sci 2018;15:1600-10 CrossRef Medline

22. Vollherbst DF, Ulfert C, Neuberger U, et al. Endovascular treatment of dural arteriovenous fistulas using transarterial liquid embolization in combination with transvenous balloon-assisted protection of the venous sinus. AJNR Am J Neuroradiol 2018;39:1296-1302 CrossRef Medline

23. Shapiro M, Raz E, Litao M, et al. Toward a better understanding of dural arteriovenous fistula angioarchitecture: superselective transvenous embolization of a sigmoid common arterial collector. AJNR Am J Neuroradiol 2018;39:1682-88 CrossRef Medline

24. Ramos AD, Sundararajan S, Santillan A, et al. Single arm access venous sinus stenting (SAVeS) technique: technical note. Interv Neuroradiol 2020;26:501-05 CrossRef Medline 
25. Yamaguchi S, Horie N, Hayashi K, et al. Point-by-point parent artery/sinus obliteration using detachable, pushable, 0.035-inch coils. Acta Neurochir (Wien) 2016;158:2089-94 CrossRef Medline

26. Alexander MD, Halbach VV, Hallam DK, et al. Long-term outcomes of endovascular treatment of indirect carotid cavernous fistulae: superior efficacy, safety, and durability of transvenous coiling over other techniques. Neurosurgery 2019;85:E94-100 CrossRef Medline

27. Hsu YH, Lee CW, Liu HM, et al. Endovascular treatment and computed imaging follow-up of $\mathbf{1 4}$ anterior condylar dural arteriovenous fistulas. Interv Neuroradiol 2014;20:368-77 CrossRef Medline

28. Moenninghoff C, Pohl E, Deuschl C, et al. Outcomes after Onyx embolization as primary treatment for cranial dural arteriovenous fistula in the past decade. Acad Radiol 2020;27:e123-31 CrossRef Medline

29. Ayad M, Eskioglu E, Mericle RA. Onyx: a unique neuroembolic agent. Expert Rev Med Devices 2006;3:705-15 CrossRef Medline

30. Rabinov JD, Yoo AJ, Ogilvy CS, et al. ONYX versus n-BCA for embolization of cranial dural arteriovenous fistulas. J Neurointerv Surg 2013;5:306-10 CrossRef Medline

31. Rangel-Castilla L, Barber SM, Klucznik R, et al. Mid and long term outcomes of dural arteriovenous fistula endovascular management with Onyx: experience of a single tertiary center. J Neurointerv Surg 2014;6:607-13 CrossRef Medline

32. Gross BA, Albuquerque FC, Moon K, et al. Evolution of treatment and a detailed analysis of occlusion, recurrence, and clinical outcomes in an endovascular library of $\mathbf{2 6 0}$ dural arteriovenous fistulas. J Neurosurg 2017;126:1884-93 CrossRef Medline

33. Bhatia KD, Wang L, Parkinson RJ, et al. Successful treatment of six cases of indirect carotid-cavernous fistula with ethylene vinyl alcohol copolymer (Onyx) transvenous embolization. J Neuroophthalmol 2009;29:3-8 CrossRef Medline

34. Jiang $\mathrm{Y}, \mathrm{Li} \mathrm{Y}, \mathrm{Wu} \mathrm{Z}$. Onyx distal embolization in transarterial embolization of dural arteriovenous fistula with subtotally isolated transverse-sigmoid sinus: a case report. Interv Neuroradiol 2009;15:223-28 CrossRef Medline

35. Brunozzi D, Alaraj A. Operative nuances of blind catheterization of occluded sinuses using negative road map technique: 2-dimensional operative video. Oper Neurosurg (Hagerstown) 2020;19:E599 CrossRef Medline

36. Borden JA, Wu JK, Shucart WA. A proposed classification for spinal and cranial dural arteriovenous fistulous malformations and implications for treatment. J Neurosurg 1995;82:166-79 CrossRef Medline

37. Lucas C. D P, Mounayer C, Spelle L, et al. Endoarterial management of dural arteriovenous malformations with isolated sinus using Onyx-18: technical case report. Neurosurgery 2007;61:E293-94; discussion E294 CrossRef Medline

38. Takemoto K, Tateshima S, Rastogi S, et al. Onyx embolization of anterior condylar confluence dural arteriovenous fistula. J Neurointerv Surg 2014;6:e13 CrossRef Medline

39. Ye M, Zhang P. Transvenous balloon-assisted Onyx embolization of dural arteriovenous fistulas of hypoglossal canal. Neuroradiology 2018;60:971-78 CrossRef Medline

40. Chapot R, Stracke P, Velasco A, et al. The pressure cooker technique for the treatment of brain AVMs. J Neuroradiol 2014;41:87-91 CrossRef Medline

41. Koyanagi M, Mosimann PJ, Nordmeyer H, et al. The transvenous retrograde pressure cooker technique for the curative embolization of high-grade brain arteriovenous malformations. J Neurointerv Surg 2021;13:637-41 CrossRef Medline

42. Castro-Afonso LH, Trivelato FP, Rezende MT, et al. The routes for embolization of dural carotid cavernous fistulas when the endovascular approach is indicated as a first-line strategy. Interv Neuroradiol 2019;25:66-70 CrossRef Medline
43. Caplan JM, Kaminsky I, Gailloud P, et al. A single burr hole approach for direct transverse sinus cannulation for the treatment of a dural arteriovenous fistula. J Neurointerv Surg 2015; 7:e5 CrossRef Medline

44. Suh DC, Lee JH, Kim SJ, et al. New concept in cavernous sinus dural arteriovenous fistula: correlation with presenting symptom and venous drainage patterns. Stroke 2005;36:1134-39 CrossRef Medline

45. Aralasmak A, Karaali K, Cevikol C, et al. Venous drainage patterns in carotid cavernous fistulas. ISRN Radiol 2014;2014:760267 CrossRef Medline

46. Robert T, Sylvestre P, Blanc R, et al. Thrombosis of venous outflows of the cavernous sinus: possible aetiology of the cortical venous reflux in case of indirect carotid-cavernous fistulas. Acta Neurochir (Wien) 2017;159:835-43 CrossRef Medline

47. Luo CB, Chang FC, Teng MM, et al. Anatomic variation of facial vein in carotid-cavernous fistula and trans-facial vein embolization. World Neurosurg 2015;84:90-96 CrossRef Medline

48. Biondi A, Milea D, Cognard C, et al. Cavernous sinus dural fistulae treated by transvenous approach through the facial vein: report of seven cases and review of the literature. AJNR Am J Neuroradiol 2003;24:1240-46 Medline

49. Uflacker R, Lima S, Ribas GC, et al. Carotid-cavernous fistulas: embolization through the superior ophthalmic vein approach. Radiology 1986;159:175-79 CrossRef Medline

50. Phan $\mathrm{K}, \mathrm{Xu}$ J, Leung $\mathrm{V}$, et al. Orbital approaches for treatment of carotid cavernous fistulas: a systematic review. World Neurosurg 2016;96:243-51 CrossRef Medline

51. Wenderoth J. Novel approaches to access and treatment of cavernous sinus dural arteriovenous fistula (CS-DAVF): case series and review of the literature. J Neurointerv Surg 2017;9:290-96 CrossRef Medline

52. Youssef PP, Schuette AJ, Cawley CM, et al. Advances in surgical approaches to dural fistulas. Neurosurgery 2014;74 (Suppl 1):S32-41 CrossRef Medline

53. Sur S, Menaker SA, Alvarez C, et al. Multimodal management of carotid-cavernous fistulas. World Neurosurg 2020;133:e796-803 CrossRef Medline

54. Kirsch M, Henkes H, Liebig T, et al. Endovascular management of dural carotid-cavernous sinus fistulas in 141 patients. Neuroradiology 2006;48:486-90 CrossRef Medline

55. Kuwayama N. Epidemiologic survey of dural arteriovenous fistulas in Japan: clinical frequency and present status of treatment. Acta Neurochir Suppl 2016;123:185-88 CrossRef Medline

56. Kim DJ, Kim DI, Suh SH, et al. Results of transvenous embolization of cavernous dural arteriovenous fistula: a single-center experience with emphasis on complications and management. AJNR Am J Neuroradiol 2006;27:2078-82 Medline

57. Lv X, Jiang C, Liang $\mathrm{S}$, et al. The variant with the absence of the superior petrosal venous and sinus: a potential pitfall of transvenous balloon-assisted embolisation of Borden type II transverse-sigmoid dural arteriovenous fistula. Interv Neuroradiol 2019;25:474-77 CrossRef Medline

58. Halbach VV, Higashida RT, Hieshima GB, et al. Transvenous embolization of dural fistulas involving the transverse and sigmoid sinuses. AJNR Am J Neuroradiol 1989;10:385-92 Medline

59. Kuwayama N, Endo S, Kubo M, et al. Pitfalls in endovascular treatment of dural arteriovenous fistulas involving the cavernous sinus. Interv Neuroradiol 1997;3(Suppl 2):88-92 CrossRef Medline

60. Liebelt BD, Barber SM, Desai VR, et al. Superior petrosal vein sacrifice during microvascular decompression: perioperative complication rates and comparison with venous preservation. World Neurosurg 2017;104:788-94 CrossRef Medline

61. Elhammady MS, Wolfe SQ, Farhat H, et al. Onyx embolization of carotid-cavernous fistulae. J Neurosurg 2010;112:589-94 CrossRef Medline 